\title{
NEGOCIAÇÃO E RESISTÊNCIA NA CIDADE DE BONNY NO SÉCULO XIX. $O$ CASO DO REI WILLIAM PEPPLE
}

\author{
Alexsander Lemos de Almeida Gebara \\ Doutor em História Social-FFLCH/USP \\ Professor da Universidade de Taubaté
}

\section{Resumo}

Este trabalho procura apresentar a dinâmica de crise do poder "tradicional" em Bonny Town ao longo do século XIX, frente às constantes interferências inglesas na política local. O objetivo é mostrar como estas relações atlânticas foram importantes para configurar a estrutura sócio política em local, enfatizando a situação de contato que domina a cena na costa ocidental africana. O trabalho também realiza uma breve apresentação da formação histórica das sociedades do delta do Níger e o principal corpo de fontes são os relatos de viagem de Richard Francis Burton, cônsul inglês na Baía de Biafra entre 1861-64, além dos relatórios consulares que se encontram no Public Record Office, em Londres.

\section{Pallavras-Chave}

África Ocidental • África • Século XIX • Delta do Níger • Viajantes

\section{Abstract}

This paper intends to present the dynamics of the crisis of "traditional" power in Bonny Town during the XIXth century, in front of the constant British interventions in local politics. The aim is to show how this Atlantic relations were important to configure the local socio political structure emphasising the situation of contact that dominates the scene in the west African coast. The work also makes a brief presentation of the historical formation of the Niger Delta societies and the main body of sources are Richard Francis Burton's travel writings, who was British consul to the Bight of Biafra within 1861-1864, and also the consular reports found at the Public Record Office in London.

\section{Keywords}

West Africa $\bullet$ Africa $\bullet X^{\text {XI }}{ }^{\text {th }}$ Century $\bullet$ Niger Delta $\bullet$ Travel Writings 
Este artigo tem como objetivo apresentar através de um exemplo específico, um pouco da complexidade da dinâmica das relações entre o delta do Níger e o mundo atlântico ao longo do século XIX, período no qual estas relações foram mediadas em grande parte pela Inglaterra. Além disto, procura mostrar também o desenrolar de uma das múltiplas possibilidades de negociação e resistência presentes para os chefes africanos. Estas possibilidades emergem como fruto de uma conjuntura de longo contato comercial atlântico e do contexto do combate ao tráfico escravo pela Inglaterra a partir de 1807.

Este tema apareceu durante o desenvolvimento de minha pesquisa de doutorado que versa sobre as imagens da África nas representações deste autor. ${ }^{1}$ Burton foi uma personagem multifacetada, tendo sido militar, explorador, membro de diversas sociedades científicas tais como a Royal Geographic Society e a Anthropological Society of London, além de cônsul, tradutor, entre outras atividades.Quando esteve na África Ocidental como representante consular inglês na Baía de Biafra entre 1861-1864, já tinha larga experiência como viajante e explorador. Foi também neste momento que reforçou suas ligações com uma "antropologia" baseada mais fortemente em determinismos biológicos que atestavam a inferioridade do não-europeu. ${ }^{2}$

A jurisdição de seu consulado, com sede em Fernando Pó (atual Bioko), incluía os então chamados Oil Rivers, ou seja, os diversos braços do delta do Rio Níger que escoavam o óleo de palma do interior para os portos de comércio atlântico nas cidades da costa. No início da década de 1860, e de fato durante boa parte do século XIX, Bonny foi o maior porto exportador de óleo de palma de toda a África Ocidental, assim, não é surpresa o fato de ter sido também

\footnotetext{
${ }^{1}$ GEBARA, Alexsander. A África presente no discurso de Richard Francis Burton, uma análise da construção de suas representações. Tese de doutorado. Departamento de História - FFLCH/USP, 2006. Pesquisa no Brasil e em Londres financiada pela CAPES.

${ }^{2}$ Para um estudo mais detalhado das filiações teóricas de Burton quanto às descrições populacionais, ver GEBARA, Alexsander Lemos de Almeida. "As representações populacionais de Richard Francis Burton - uma análise do processo de constituição do discurso sobre populações não européias no século XIX”. Revista de História, n. 149, 2004, pp. 181-209. A respeito de sua vida em geral, ver, entre outros: BROADIE, Fawn. The Devil Drives. New York: Norton, 1984, RICE, Edward. Sir Richard Francis Burton, o Agente Secreto que Fez a Peregrinação a Meca, Descobriu o Kama Sutra e Trouxe as Mil e Uma Noites para o Ocidente. São Paulo: Cia. das Letras, 1991.
} 
esta cidade um dos maiores focos de intervenção inglesa, mesmo antes do período colonial propriamente dito.

Durante minha pesquisa de doutorado já mencionada pude acompanhar mais de perto os desenvolvimentos ocorridos em Bonny, quer através dos documentos consulares produzidos por Burton, quer através de parte da historiografia da região, dentro dos limites possíveis pelo tempo e pela relevância do tema dentro de minha tese. Desta forma, o que apresento aqui são algumas vicissitudes de William Pepple, Rei de Bonny entre as décadas de 1830-1860. Para isto, entretanto, faz-se necessário apresentar, ainda que brevemente, como se constituíram as estruturas sócio-políticas do Delta do Níger, mostrando como estas vinham se transformando ao longo do tempo, especialmente durante a era de contato com as demandas comerciais atlânticas.

\section{Breve histórico do Delta do Niger e contextualização das relações comerciais e políticas entre Bonny e Inglaterra na década de 1860}

De acordo com E. J. Alagoa, o início do povoamento da região costeira do Delta pode ser localizado por volta do século XII, através de migrações das regiões interiores próximas. Concomitantemente a esta migração, houve também a mudança na organização produtiva da tradicional vila fazendeira do interior para as vilas de pescadores no litoral. Esta transformação das comunidades teria ocorrido em razão das diferenças geográficas entre as regiões. ${ }^{3}$

De fato, apesar de datar de cerca de três séculos antes o início mais significativo do povoamento, Alagoa concorda com K. O. Dike sobre a forma de adensamento desta população, que teria ocorrido através de migrações seqüenciais, especialmente a partir do século XV. Contudo, a maior antiguidade do povoamento da região permitiu à Alagoa considerar que a configuração das instituições de governo e organização das sociedades do Delta fossem também anteriores ao contato comercial com os europeus e às demandas atlânticas, e que as transformações das ‘vilas’ em ‘cidades estado’ fossem mudanças oriundas do comércio interno de longa distância, e não do comércio atlântico. ${ }^{4}$

\footnotetext{
${ }^{3}$ ALAGOA, E. J. "The Development of Institutions in the States of the Eastern Niger Delta." The Journal of African History, vol. 12, no 2, 1971, pp. 269-278.
}

${ }^{4}$ ALAGOA, E. J. “The Development of Institutions...”, op. cit., p. 269. 
A unidade política básica no interior eram as 'vilas fazendeiras'. A autoridade maior era conferida à assembléia geral, na qual todos os membros masculinos adultos da comunidade tomavam parte. Esta assembléia era presidida pelo mais velho dos membros da linhagem fundadora da vila, intitulado "Amanyanabo". Além da autoridade da assembléia, várias linhagens familiares compunham a estrutura hierárquica da vila. O pertencimento à determinada família era importante porque o direito sobre as terras cultiváveis residia, justamente, na linhagem. ${ }^{5}$ Cada uma das vilas era totalmente autônoma, não havendo autoridade política geral sobre elas.

Com a mudança para as regiões costeiras, algumas transformações tiveram lugar. A presidência da assembléia não recaía mais necessariamente sobre o membro mais velho, embora o cargo continuasse a ser privilégio da linhagem fundadora. Entretanto, a organização produtiva não se baseava mais na terra cultivável, pela simples razão da escassez deste recurso nos mangues costeiros. As novas fontes produtoras, quais sejam, rios e riachos próximos à vila eram explorados de forma comunal, o que ampliou a solidariedade interna das vilas, ao mesmo tempo em que diminuiu a importância da restrição das linhagens, tornando mais fácil a inclusão de novos membros. Outra transformação importante também deriva da relação com os recursos naturais, a saber, a ampliação das estruturas de defesa resultante das constantes brigas e embates entre as vilas pelo domínio dos rios e riachos.

Desta forma, ainda segundo Alagoa:

... podemos vislumbrar os estados como resultante de uma das vilas pescadoras gradualmente construindo uma dominância sobre seus vizinhos. Tal comunidade tornou-se o centro de população, de comércio, riqueza e poder. ${ }^{6}$

$\mathrm{O}$ argumento de Alagoa é que as instituições que conformavam estes pequenos "estados" já estavam consolidadas antes do advento do comércio atlân-

\footnotetext{
${ }^{5}$ ALAGOA, E. J. "The Development of Institutions...”, op.cit. , p. 270.

6 “....we can envisage the states as resulting from one of the fishing villages gradually building dominance over its neighbors. Such a community became the centre of the population, of trade, wealth, and of power.' Idem, p. 272. Para preservar o texto original, as citações traduzidas no corpo do texto encontram-se em sua língua original nas notas.
} 
tico, num momento no qual o comércio interno com o interior era mais importante, e estabelecido por aquelas antigas vilas que conseguiram organizar-se internamente o suficiente para constituir relações com comunidades produtoras do interior e assegurar domínio sobre as rotas de comércio. Desta forma, quando se deu o início da demanda atlântica, eram estas localidades que estavam prontas para envolverem-se neste novo tipo de comércio. ${ }^{7}$

Obviamente, conforme a intensidade do comércio atlântico aumentou, as transformações internas nas sociedades costeiras do Delta também aceleraram. Estas mudanças se deram, de maneira geral, em dois aspectos: o primeiro deles foi o aumento das funções do Amanyanabo (rei), que passou a controlar os interesses econômicos do Estado, bem como a organização geral de sua defesa; o segundo foi no sistema das linhagens ("House sistem”), tornando-as intimamente ligadas ao comércio. A escolha dos chefes das "linhagens" passou a seguir critérios econômicos, o recrutamento de membros externos tornou-se cada vez mais comum - mesmo que constituídos de escravos - e importante para o fortalecimento da 'linhagem', e enfim, o controle sobre seus membros passou a ser cada vez mais forte. ${ }^{8}$ Esta dinâmica sugere que a densidade populacional continuou a aumentar durante o período do tráfico atlântico. Entretanto, estes novos afluxos de população seriam constituídos, em sua grande maioria, por escravos, em parte para suprir a demanda atlântica e em parte para agregar poder às casas instituídas, o que aconteceu em especial no período de combate ao tráfico de escravos pelo esquadrão britânico para a África ocidental, de 1807 em diante.

Segundo Dike, é importante notar que uma parcela desta população imigrante não escrava estabeleceu-se um pouco mais para o interior, de onde passaram a atuar como atravessadores no comércio do interior africano com a costa. ${ }^{9}$ Esta parte da população, denominada Aros, assumiu grande importância, uma vez que dominavam as instituições religiosas e eram temidos por quase toda a população costeira.

Como resultado do desenvolvimento do comércio atlântico e das ondas migratórias seqüenciais, a região do Delta do Níger tornou-se um espaço muito povoado. Constituiu-se então uma região especializada no comércio, com um

\footnotetext{
${ }^{7}$ Idem, p. 273.

${ }^{8}$ Idem, p. 274-275.

${ }^{9}$ DIKE, Trade and Politics in the Niger Delta, Oxford: Clarendon Press, 1956, p. 16
} 
excedente populacional que veio a suprir parte da demanda escrava com o incremento do tráfico atlântico, principalmente a partir do século XVII.

Apesar da maioria da população e da língua utilizada na maior parte das cidades serem de origem Ibo, segundo Dike, a "população que surgiu desta mistura de povos não era nem Efick, Ibo, ou Ibibio". Seriam um povo à parte, que havia resultado do encontro cultural das tribos do interior com as comunidades costeiras. ${ }^{10}$ Por esta razão estas comunidades não se identificavam mais apenas pela origem, mas também pela continuidade de coabitação numa mesma região, adaptando, com o passar do tempo, as organizações anteriores em estruturas que possibilitavam o desenvolvimento comercial nos moldes do tráfico atlântico ao longo dos 400 anos de sua existência. Certamente as variações étnicas e culturais geravam outros tipos de configuração de identidades bastante mais complexas, entretanto, o objetivo neste texto aqui é apenas explicar, em termos gerais, a organização política e econômica que durante este tempo esteve imposta à diferentes etnias possivelmente presentes numa mesma cidade.

A estrutura fundamental da organização social no Delta do Níger era, portanto, o chamado “house sistem". Este 'sistema de linhagens' tornou-se como se viu, ao mesmo tempo, uma cooperativa de comércio e uma instituição de governo local. Cada unidade era formada pela família estendida do seu 'chefe', que tinha poderes soberanos sobre os outros membros e representava a 'linhagem' na assembléia da cidade, além de agregar também seus escravos, que nas maiores delas variavam entre 300 e 1000. Era parte desta estrutura também a constituição de uma força militar, baseada em canoas de guerra. ${ }^{11}$ Uma mudança significativa resultante da dinamização do comércio foi justamente a característica de abertura destas linhagens, ou “casas”, a membros exteriores, com intuito de fortalecer o seu poder econômico e militar. As possibilidades de ascensão social pareciam ser bastante amplas, com ex-escravos podendo ascender inclusive a posições de comando militar. ${ }^{12}$

\footnotetext{
10 "the population that evolved out of this mingling of peoples was neither Benim nor Efick, Ibo, nor Ibibio. They were a people apart, the product of the clashing cultures of the tribal hinterland and of the Atlantic community to both of which they belonged..." DIKE, Trade and Politics..., p. 30.

${ }^{11}$ Estas 'canoas de guerra' levavam entre 80 e 140 guerreiros armados e muitas vezes uma arma de calibre grande na proa da embarcação. Segundo Mbaeyi, chegavam a impressionar europeus ainda no século XIX. MBAEYI, Paul, M. British military and naval forces in West African History 1807-1874. London: KOK Publishers, 1978, capítulo 1.
}

${ }^{12}$ ALAGOA, Development of Institutions.... p. 273. 
Esta organização era semelhante no interior próximo a costa e, segundo o autor, as populações Ibo interioranas dominavam - além das atividades religiosas - a captura e distribuição de escravos, o que fazia com que predominassem politicamente sobre as cidades costeiras, dependentes deste fornecimento. Este equilíbrio político seria transformado somente pelo aumento da importância do comércio de óleo de palma em detrimento do tráfico escravo, a partir da década de 30 do século XIX.

Discussões ulteriores na historiografia econômica da África não parecem contradizer esta interpretação, embora apresentem algumas diferenças com relação à análise de Dike, especialmente no que diz respeito à diminuição do tráfico escravo na década de 1830. Lovejoy e Richardson encontraram, de fato, uma crise no comércio escravo na região das baías de Benim e Biafra, mas localizam-na apenas na década posterior à proibição do tráfico pela Grã Bretanha, e depois apontam para um preço e volume relativamente constantes até ao menos a década de $1850 .{ }^{13}$ De fato, estes autores notam uma mudança apenas no sentido do comércio, sugerindo que a demanda no interior africano teria aumentado e este seria um dos fatores influentes na manutenção do preço, mesmo com a oferta de escravos tendo crescido nas décadas de 1830 e 1840, devido a desintegração do império Oyo e também à situação de guerra endêmica no interior em razão da expansão do estado muçulmano Fulani. Por sua vez, Martin Lynn aponta para uma continuação da estrutura de comércio entre os africanos da costa e os mercadores ingleses durante o período. ${ }^{14}$

Durante a década de 1830, outro fator começou a intervir mais ativamente na correlação de forças políticas na região do Delta do Níger, qual seja, o esquadrão britânico para a África Ocidental e a conseqüente política britânica de imposição de tratados contra o tráfico de escravos junto aos chefes locais. A primeira interferência significativa foi na cidade de Bonny - que concentrava a maior parte do comércio regional, tanto de escravos, quanto de óleo de Palma

${ }^{13}$ LOVEJOY, P. and RICHARDSON, D. The initial 'crisis of adaptation': the Impact of British Abolition on the Atlantic Slave Trade in West Africa. In: LAW, R. From Slave Trade to 'Legitimate' Commerce, the Commercial Transition in Nineteenth Century West Africa. Cambridge: Cambridge University Press, 1995, pp. 32-56.

${ }^{14}$ LYNN, Martin. "The West African Palm Oil trade in the nineteenth century and the "crisis of adaptation"' In LAW, R. From Slave Trade to 'Legitimate' Commerce, the Commercial Transition in Nineteenth Century West Africa. Cambridge: Cambridge University Press, 1995. 
- durante a invasão do porto da cidade para aprisionar navios negreiros espanhóis, em janeiro de $1836 .{ }^{15}$

A situação política em Bonny era relativamente complexa. Em 1830 havia morrido o rei instituído, Opobu Pepple, que como se viu era necessariamente pertencente à linhagem fundadora. Seu filho e legítimo herdeiro, William Pepple, ainda não tinha idade suficiente para assumir as funções, tendo assumido em seu lugar um regente temporário, que era ex-escravo da casa Pepple, chamado Madu. Quando este morreu três anos depois, tal era o controle do Estado que ele havia desenvolvido, que seu filho, Alali, foi quem assumiu em seu lugar em detrimento do herdeiro legítimo. As opiniões estavam divididas em Bonny, por um lado, uma parcela da população que defendia a permanência de Pepple no poder e, por outro, grupos e comerciantes que tendiam a identificar-se com Alali. ${ }^{16}$

O fato é que quando da invasão do porto de Bonny pelos navios britânicos foi Alali quem reagiu contra esta intervenção, aprisionando o comandante do navio e exigindo explicações. A consequiência deste acontecimento foi a pressão realizada pelo esquadrão contra Bonny nas semanas seguintes e a interferência direta na política local, forçando a assinatura de um tratado de proteção da vida e propriedade britânica, depondo o regente anterior (Alali) e instaurando o rei William Pepple em seu lugar, que se viu posteriormente obrigado a fazer concessões às pretensões políticas e comerciais britânicas. Desta forma, logo a seguir, em 1839, houve a assinatura de um novo tratado, com intuito de por fim ao tráfico escravo, assegurando o pagamento de 2 mil dólares por ano pela Inglaterra à Bonny, durante 5 anos, como forma de recompensa.

Divisões internas de opinião no $F$. $O$., entretanto, fizeram que as responsabilidades inglesas no tratado não fossem cumpridas e esta continuou sendo a tônica das relações durante a década seguinte. A Inglaterra continuava procurando fazer tratados com estados locais visando tornar 'legal' a atuação do seu esquadrão na costa (somente em Bonny, três diferentes acordos foram assinados entre 1839 e 1848), e as divisões internas nas sociedades costeiras africanas

\footnotetext{
${ }^{15}$ A Inglaterra havia assinado um tratado com a Espanha no ano anterior, que lhe permitia a apreensão de navios escravistas espanhóis.

${ }^{16}$ DIKE, Trade and Politics..., capítulo 4. Dike sugere que ao lado de William Pepple, cerraram fileiras uma espécie de elite de linhagem, e com Alali ficaram a massa da população escrava ou ex-escrava.
} 
resultavam, ora num sentimento profundamente anti-britânico, e ora na solicitação de apoio para manutenção de poder de determinados grupos. ${ }^{17}$

De qualquer forma, as relações comerciais continuavam acontecendo nas mesmas bases de antes, como descritas por Martin Lynn, ou seja, pelos antigos escravistas, numa espécie de oligopólio das companhias de Liverpool e baseado no conhecimento pessoal dos grandes comerciantes africanos na costa. A diferença era que os comerciantes ingleses podiam recorrer ao suporte do braço armado do Estado britânico na região, o esquadrão africano, especialmente depois de 1849, com a instalação do primeiro consulado para as Baías de Benim e Biafra. Isto mudava a correlação de forças no comércio, pois desde o tempo do tráfico escravista inglês este estava baseado numa relação de igualdade entre as partes comerciantes, sendo de fato o lado mais fraco até então o dos comerciantes europeus, que não tinham direito sobre a terra nem estrutura de defesa com a qual pudessem fazer frente aos estados costeiros.

Novas transformações aconteceram na década seguinte, graças a fatores como instalação de estabelecimentos de comércio com residentes permanentes que facilitavam a captação e estocagem da mercadoria vinda do interior. Além disto, também foi importante a fundação de casas de comissão, que forneciam adiantamentos a comerciantes fixos na região em troca do direito de revender a produção na Europa. Finalmente, a principal delas foi a fundação da African Steamship Company, firma de navegação à vapor de McGregor Laird, em 1852. Esta companhia tornou o frete muito mais barato e permitiu a entrada de pequenos comerciantes no negócio de óleo de palma, antes reservados à grandes firmas, dada a necessidade de capital investido nos navios que faziam a transferência da produção para a Europa. ${ }^{18}$ Em 1856, apenas 4 anos após a fundação da companhia, havia mais de 200 firmas de comércio atuando na região, onde antes apenas algumas dezenas atuavam.

\footnotetext{
${ }^{17}$ DIKE, Trade and Politics..., capítulo 4. Este foi o caso de Pepple na década de 30, que utilizou-se da pressão britânica para retomar o poder em Bonny.

${ }^{18}$ LYNN, The West African Palm Oil Trade..., p. 66. Ver também do mesmo autor "From Sail to Steam: the Impact of the Steamship Services on the British Palm Oil Trade with West Africa, 1850-1890. The Journal of African History. Vol. 30, n 2, 1989, pp. 227-245.
} 
Some-se a isto a afluência de pequenos comerciantes africanos de Serra Leoa, ${ }^{19}$ desejosos de participar do comércio. O resultado foi uma verdadeira 'guerra' entre comerciantes das grandes firmas de Liverpool, que praticamente monopolizavam o comércio da região, desde o período do tráfico escravo, e pequenos comerciantes interessados em participar do rentável negócio do óleo de palma. Estes últimos, por sua vez, ofereciam preços melhores pelos carregamentos do interior e 'cortavam' a relação de crédito (trust) entre as firmas maiores e os atravessadores africanos. Os encarregados das grandes firmas recorriam sempre que possível ao cônsul instalado em Fernando Pó, e o padrão geral de atuação destes tendeu a ser, entre o final da década de 50 e começo da seguinte, sempre em favor dos grandes mercadores e contrário aos pequenos e, muitas vezes, aos próprios chefes comerciantes africanos. ${ }^{20}$

Havia ainda uma outra condição que significou uma grande mudança nas relações comerciais na região e um desafio à proeminência das cidades costeiras, qual seja, o incentivo de cônsules e representantes da Inglaterra para a realização da comercialização direta com o interior, procurando evitar o papel dos atravessadores dos africanos da costa, o que fez com que estes continuassem tentando resistir ao máximo à penetração européia. ${ }^{21}$

Foi neste contexto de profunda transformação econômica e das relações de poder entre a Europa e os estados costeiros africanos - que internamente também refletiam as pressões políticas e transformações econômicas em curso - que Burton foi indicado cônsul Fernando Pó, em abril de 1861. Sua indicação foi para substituir o cônsul Thomas Joseph Hutchinson que tradicionalmente

\footnotetext{
${ }^{19}$ Boa parte destes pequenos comerciantes eram ex escravos capturados pelo esquadrão naval britânico e libertados em Serra Leoa e algumas vezes seus descendentes. Ver LYNN, Martin. “Technology, Trade and a 'Race of Native Capitalists': The Krio Diaspora of West Africa and the Steamship, 1852-95". The Journal of African History, vol. 33, n 3, 1992, pp. 421-440.

${ }^{20}$ DIKE, Trade and Politics..., p. 122 e seguintes. Estas atuações referem-se principalmente ao cônsul Hutchinson, anterior à presença de Burton no consulado. Em determinada situação, após uma reclamação de retornados de Serra Leoa sobre a interferência consular em favor dos mercadores de Liverpool, em despacho interno do Foreign Office, Clarendon escreveu: "Em que bases o cônsul interferiu? Os mercadores sabem dos riscos que correm com o sistema de crédito, e não seria melhor deixá-los resolver seus próprios problemas com os nativos até que o F.O. permita ao cônsul intervir?" Apud. DIKE,Trade and Politics..., p. 123.

${ }^{21}$ Há episódios nas correspondências entre Burton e o Foreign Office nas quais fica relativamente clara a proposição da comercialização direta com o interior, bem como a resistência por parte dos africanos.
} 
colocava-se ao lado dos representantes das firmas de Liverpool e que foi destituído de seu cargo por suspeitas de defender estes interesses em troca de proveito pecuniário próprio. ${ }^{22}$

Um dos principais centros comerciais do Delta do Níger era a cidade de Bonny, localizada na parte leste da região. Por volta da década de 1830, esta localidade respondia por aproximadamente um terço do volume total de óleo de palma exportado por toda a costa ocidental africana. ${ }^{23}$ Como se viu, a organização política do Delta vinha se transformando ao longo dos séculos de desenvolvimento do comércio atlântico, em especial com a ampliação dos poderes do rei e com a 'abertura' cada vez maior do sistema de linhagens (House sistem) à penetração de membros exteriores ao grupo sanguíneo original. Uma das consequiências destas transformações foi o domínio econômico da linhagem principal sobre as demais, e a ocupação de lugares administrativos importantes por elementos externos à linhagem consangüínea, juntamente com um grande afluxo populacional composto de 'escravos' que, agregados às diferentes linhagens fortaleciam a posição destas na hierarquia interna.

No século XIX, proeminência econômica e política eram praticamente sinônimos em Bonny, uma vez que uma das prerrogativas do rei era o controle dos interesses econômicos do Estado. ${ }^{24}$ No início da década de 1830, a linhagem Pepple estava em seu terceiro rei, conseguindo desta forma um grande acúmulo de poder sobre as demais linhagens no pequeno Estado costeiro. Até então, a cidade mantinha-se senhora da situação comercial, vendendo tanto óleo de palma como escravos, respondendo à demanda atlântica. Mas este também foi um período bastante conturbado para a política e o comércio em Bonny por dois motivos principais que tornaram-se interligados: uma crise na sucessão ao trono e a interferência do esquadrão naval britânico.

\footnotetext{
${ }^{22}$ Ver NEWBURY, C.W. "Introduction”. In: BURTON, Richard. A mission to Gelele King of Dahome, London: Routledge, 1966.

${ }^{23}$ LYNN, Martin. "Change and Continuity in the British Palm Oil Trade with West Africa, 1830-1855". The Journal of African History, vol. 22, n. 3, 1981, pp. 331-348. Tabela na p. 341. Em outro artigo deste mesmo autor pode-se inferir que por volta da década de 50 Bonny continuava como o maior porto exportador de óleo da África, com cerca de $15 \%$ do total. Lynn, M. "From Sail to Steam: the Impact of the Steamship Services on the British Palm Oil Trade with West Africa, 1850-1890. The Journal of African History. Vol. 30, n 2, 1989, pp. 227-245.

${ }^{24}$ ALAGOA, E. J. The Development of Institutions..., pp. 270-273.
} 
Como se viu, Pepple reassumiu o trono através da interferência inglesa, que depusera Alali, e exigira em troca um acordo para por fim ao tráfico escravo. Pepple, por sua vez, apesar de ter firmado tal acordo, não parecia muito disposto a cumpri-lo. O comércio de escravos continuou a existir ainda que em volume diminuído. A Inglaterra, por sua vez, também não cumpriu a sua parte do acordo - o pagamento anual de compensação em dinheiro - o que tornava a situação política de Pepple delicada, desenvolvendo uma oposição à aproximação com a Inglaterra cada vez mais forte, também entre os aliados do rei. Ao longo da década de 1840, iniciou-se uma verdadeira operação de guerrilha na rede de rios próximas à Bonny, com constantes ataques à mercadores ingleses. ${ }^{25}$

Finalmente, a nomeação de John Beecroft como primeiro cônsul inglês para as baías de Benim e Biafra tornou a situação de tentativa de resistência direta em Bonny insustentável, pois o esquadrão passou a atuar de forma bem mais incisiva a partir deste momento. Em 1854, Beecroft acabou depondo o rei que a própria Inglaterra tinha levado ao poder, mandando-o para o exílio, parte do qual Pepple passou na Inglaterra. A situação política em Bonny ficou completamente desorganizada e as dificuldades para os comerciantes continuavam a aumentar, o que significava que os africanos ainda dispunham de certo poder sobre a dinâmica comercial, resistindo às imposições inglesas. Desta forma, apesar do aumento do volume de comércio nos anos seguintes, os próprios representantes comerciais britânicos começaram a solicitar a volta do rei, como forma de reassumir uma posição de negociação mais poderosa. Cerca de sete anos depois, William Pepple seria reempossado, pouco antes de Richard Francis Burton chegar à costa africana e iniciar seu trabalho como cônsul.

\section{Burton e a ação consular}

A primeira visita de Burton à cidade ocorreu ainda em dezembro de 1861. Nesta circunstância, o cônsul relatou ao F.O que William Pepple estava vivendo com uma pequena corte - a qual contava inclusive com duas mulheres inglesas

\footnotetext{
${ }^{25}$ Nesta década, o esquadrão africano voltou a intervir, aprisionando e deportando o chefe religioso que comandava as ações de guerrilha no interior.
} 
- e que para sustentar esta situação, gastava cerca de 5 mil libras por ano "na esperança de cobrir os gastos com precárias taxas de comércio". ${ }^{26}$

A série de correspondências sobre a situação de Bonny serve para exemplificar as dificuldades de comunicação entre o cônsul e o F.O., geradas pela demora no trânsito destes despachos entre África e Europa. Antes mesmo de receber o primeiro despacho de Burton, mencionado acima, Russell já havia encaminhado ao cônsul, em fevereiro de 1862, as reclamações da African Steamship Company sobre uma cobrança supostamente irregular de tarifas comerciais em Bonny, que estavam incidindo sobre um navio da companhia encarregado do reabastecimento dos demais vapores que faziam o trajeto Inglaterra-África Ocidental. ${ }^{27}$

Burton, no entanto, só acusou o recebimento desta correspondência que ordenava que procedesse imediatamente para Bonny, em 22 de maio de 1862, cerca de cinco meses depois do motivo da queixa ter se originado. ${ }^{28} \mathrm{~A}$ resposta do cônsul para Russell, que por sua vez só chegou ao F.O. no dia 10 de julho, dizia ser impossível o deslocamento para Bonny naquele momento, pois não havia nenhum cruzador disponível, além do fato de que estavam no período mais crítico com relação a febre amarela. ${ }^{29}$

Aparentemente, Pepple iniciou a demanda da tarifa sobre o navio da African Steamship entre dezembro e janeiro de 1862, logo após a passagem de Burton pela cidade, pois, caso contrário, a reclamação da companhia poderia ter sido feita para o cônsul em pessoa. Assim, pode ter sido uma estratégia do rei esperar o cônsul deixar Bonny antes de iniciar a cobrança. Ele havia estado exilado na Inglaterra e sabia da demora necessária para a circulação de correspondências.

\footnotetext{
${ }^{26}$ Public Record Office(PRO), Foreign Office(FO), 84/1176, 14/01/62. Além destas condições, o que chamou a atenção de Burton foram as marcas de sacrifícios humanos, através da exposição de crânios e ossos na fachada da cidade.

${ }^{27}$ PRO, FO. 84/1176, 26/02/62. A companhia, por sua vez, escrevera em 12 de fevereiro para Russell.

${ }^{28}$ Contando cerca de um mês de viagem entre o Delta do Níger e Inglaterra, a comunicação deve ter saído de Bonny no início de janeiro, chegado à Liverpool no início de Fevereiro, e a Londres no dia 12 daquele mês. No dia 26 de fevereiro Russell escreveu à Burton, que por sua vez só acusa o recebimento em 22 de maio. Não fica claro o motivo da demora de 3 meses entre o envio de Russell e o recebimento de Burton.
}

${ }^{29}$ PRO, FO. 84/1176, 22/05/62. 
De fato, Burton só retornou à Bonny no final de outubro de 1862, depois de receber outras correspondências relativas à questões comerciais e políticas na localidade. O F.O. encaminhou para seu cônsul na baía de Biafra uma série de solicitações feitas em nome de Pepple por um certo Mr. Thwaites, que reclamava neste documento o reconhecimento oficial de representante consular de Bonny na Inglaterra. ${ }^{30}$ Nestas solicitações, Thwaites além de enfatizar o direito de cobrança da tarifa sobre o mencionado navio da African Steamship Company, solicitava ajuda ao esquadrão africano na contenção de sacrifícios humanos e, por fim, avisava que Pepple pretendia aumentar ainda mais as tarifas comerciais para incrementar a arrecadação de seu reino. Esta última informação aparecia com a seguinte justificativa:

No que diz respeito às novas tarifas, o rei desistiu de ser comerciante; e os pesados encargos sobre ele para pagar os presentes que envia mais acima no país, as melhorias na cidade e na beira do rio, o compelem a aumentar a comey; ele também está ansioso para construir escolas, as quais não podem ser feitas sem dinheiro, e é claro que quando ele mesmo era comerciante isto era uma grande fonte de lucro para ele. ${ }^{31}$

É provável que justificativas, tais como, "melhoramentos na cidade e na margem do rio" e "construção de escolas", não tivessem sido utilizadas não fosse o contato que Pepple havia tido com a Inglaterra durante seu tempo de exílio. De fato, são motivações que se encaixam com perfeição no discurso missionário e humanitário. Por outro lado, Pepple encontrava-se em situação pouco favorável, pois embora fosse nominalmente regente de Bonny, não possuía grandes fontes de arrecadação, o que deixava sua linhagem enfraquecida. A não participação no comércio, antes de ser uma opção do próprio rei, devia-

\footnotetext{
${ }^{30}$ Segundo Dike, Thwaites era um Quaker, parte de um grupo que tinha se encarregado de tutelar Pepple durante sua estada na Inglaterra. DIKE, K. Trade and Politics...

31 "Respecting to the new tariff, the King has given up trading himself; and the heavy calls upon him for presents to send up the country, improvements in the town, river side, etc..., compel him to increase the comey; and he is also anxious to built schools, which cannot be done without money, and of course when he traded himself it was a large source of profit to him." F.O. 84/1176, 23/07/62, anexo 1. "Comey" é um termo que significa uma espécie de tarifa cobrada dos europeus pelos estados costeiros africanos.
} 
se aparentemente muito mais à limitações conjunturais. Afastado durante mais de seis anos da costa africana, perdera suas relações comerciais com o interior que garantia o fornecimento de óleo para vender aos ingleses, ao mesmo tempo em que enfraquecera suas ligações com os próprios comerciantes ingleses. Como se viu, sem suporte econômico era muito difícil exercer de fato o poder em Bonny.

O pedido de ajuda para acabar com "sacrifícios humanos" que consta da mesma correspondência de Thwaites fornece uma indicação da situação de Pepple. É possível que houvesse uma razão por trás de uma eventual vontade do regente de realmente acabar com estes costumes, qual seja: ao trazer novamente o esquadrão africano para secundar uma de suas propostas, Pepple tentava associar-se ao poderio britânico e de certa forma criar condições de exercer a autoridade perdida durante sua ausência. ${ }^{32}$

Infelizmente para Pepple o cônsul inglês na região não era nem um pouco permeável à argumentação filantrópica e humanitária de Thwaites. A resposta de Burton após sua passagem por Bonny foi, em sua totalidade, contrária às demandas do regente africano. O cônsul não concordava com a legalidade do pagamento da tarifa pelo navio da companhia, nem com qualquer aumento na cobrança de taxas comerciais. Para Burton, a situação em Bonny estava degenerando por culpa de seu regente. Segundo ele:

Durante os últimos sete ou oito meses o comércio tem estado quase parado no rio, principalmente devido às inconstâncias do rei, o qual, totalmente desmoralizado por uma longa residência na Inglaterra, ameaça em todas as ocasiões contratar um advogado, ou abrir um processo, ou com uma escola ou missionário. ${ }^{33}$

\footnotetext{
${ }^{32} \mathrm{O}$ F.O. por outro lado, parece ter feito leitura semelhante das solicitações de Pepple. Apesar de considerar legítima e digna de suporte a intenção de acabar com os sacrifícios humanos, Russell fez uma ressalva à Burton, que deveria informar ao regente de Bonny que "Her Majesty Government have no wish or intention to give him political support." PRO, FO 84/1176, 23/10/62.

33 "During the last seven or eight months trade has been almost stopped in the river, chiefly owing to the vagaries of the King, who, thoroughly demoralized by a long residence in England, threatens on all occasions an attorney, or a civil suit, a school or a missionary." PRO, FO, 84/ $1176,18 / 12 / 62$.
} 
Como é possível perceber, Burton considerava a estadia de Pepple na Inglaterra como algo desmoralizante. Suas críticas à postura do regente africano estão associadas em geral à suas referências a instituições inglesas que deveriam ser aplicadas em Bonny, tais como advogados, processos civis e escolas. ${ }^{34}$

Quanto a demanda de Thwaites por um representante consular de Bonny na Inglaterra, sob argumento de que Pepple sempre havia permitido a entrada do cônsul inglês em seus domínios, Burton respondeu de maneira ainda mais radical:

Isto pode soar bonito em Higbury Terrace; em Bonny entretanto, é tão arrogante quanto absurdo. rei Pepple é um pequeno chefe comerciante, filho de um pequeno chefe comerciante, rei de uma cidade suja que guarda as mesmas proporções para Benim e Biafra que a Ilha de Man para o Reino Unido. As 'melhorias na cidade e na beira do rio, etc...', são meras invenções. Bonny ainda é o lugar mais sujo e bárbaro nesta costa. ${ }^{35}$

Há um claro exagero por parte de Burton, pois Bonny era o principal porto exportador de óleo de palma de toda a costa africana ocidental, e o capital britânico comprometido com a localidade embora relativamente pequeno se comparado com o comércio externo inglês não deixava de ser importante em números absolutos. ${ }^{36}$ Além disso, embora Pepple estivesse com sua autoridade de fato comprometida, a "casa" a qual pertencia havia sido bastante forte até a geração anterior.

\footnotetext{
${ }^{34}$ Burton tinha profunda aversão à demanda por igualdade na África. Uma demanda sustentada por argumentos humanitários e missionários, em geral associada à Serra Leoa. Pepple, além disto, para piorar sua imagem frente à Burton, vestia-se à européia, e em sua corte havia mesmo algumas mulheres inglesas. Finalmente, o autor também sugeria a idéia de que qualquer "mistura" de "raças" ou "culturas" era um elemento que resultava em degeneração. Para esta opinião de Burton, ver GEBARA, Alexsander. A Experiência do Contato. As Descrições Populacionais de Richard Francis Burton, dissertação de mestrado, FFLCH, USP, 2001. 35 “This may sound well in Highbury Terrace; in Bonny it is as arrogant as it is absurd. King Pepple is a petty trading chief, son of a petty trading chief, King of a dirty town which bears the same proportion to Benim and Biafra as the Isle of Man to the United Kingdom. The 'improvements in town, river-side, etc'..., are mere inventions. Bonny is still the filthiest and the most barbarous place upon this coast." FO, 84/1176, 18/12/62.

${ }^{36} \mathrm{O}$ próprio Burton fornece os seguintes números: "Bonny contém, talvez, 500.000 libras esterlinas em propriedades britânicas, e exporta anualmente, no mínimo, 600.000 libras em óleo de palma”. FO, 84/1176, 18/12/62.
} 
A utilização de argumentos humanitários e o pedido de auxílio ao esquadrão naval britânico por parte do regente de Bonny podem ser vistos como reflexos de uma conjuntura de profunda transformação na estrutura política da localidade, resultante de mais de duas décadas de constante intervenção inglesa. Pepple manejava no interior de um padrão intervencionista ao qual esteve submetido, para assegurar sua proeminência pessoal sobre o estado de Bonny, mas o F.O. parecia disposto a intervir apenas para garantir o fluxo comercial. Ao mesmo tempo, a disposição negativa de Burton com os argumentos utilizados tornaram esta estratégia um tanto ineficaz.

Aparentemente, Pepple foi perdendo cada vez mais sua influência nos anos seguintes, a ponto de em 1867, Ja Ja, um ex-escravo que havia sido comprado por Alali ainda durante a década de 1830, comandou uma cisão na cidade de Bonny, e retirou-se, junto com algumas outras "casas" para a localidade onde fundou Opobo, cidade que rapidamente ampliaria suas bases de comércio de óleo de palma, superando a própria Bonny. ${ }^{37}$

Ja Ja e outros mercadores de Opobo passaram a controlar as redes comerciais no interior, e mantiveram o comércio funcionando nos moldes já "tradicionais" até a década de 1890, mostrando, portanto, resistência à penetração inglesa até mesmo alguns anos após a declaração da região como protetorado. ${ }^{38}$

É possível, assim, perceber que houve uma dinâmica intervencionista inglesa visando configurar a seu favor a dinâmica de comércio, mas que interferia profundamente nas relações políticas locais. Por outro lado, estas transformações também refletiam uma disputa interna dentro de um sistema político profundamente marcado pelas tradições africanas. Também é possível notar que diferentes estratégias podem ser vislumbradas por parte dos nativos de Bonny, desde uma adaptação ao discurso missionário humanitário tentado por William Pepple, até a resistência para a manutenção e ampliação do controle comercial no caso de Ja Já.

\footnotetext{
${ }^{37}$ FLINT, John. “African Historians and African History”. Past and Present, n 10, 1956, pp. 96-101. ${ }^{38}$ GERTZEL, Cherry. "Relations Between African and European Traders in the Niger Delta 1880-1896. The Journal of African History, vol. 3, n 2, 1961, pp. 361-366. De acordo com a interpretação de Gertzel, as relações comerciais satisfaziam tanto africanos quanto europeus. Uma crise no preço do óleo, entretanto, fez com que Ja Ja procurasse comercializar direto com a Europa ao redor de 1885, para ampliar suas margens de lucro. Esta atitude foi, segundo este autor, o estopim para a deportação de Ja Ja de Opobo, em 1887.
} 
A posição de Pepple talvez possa ser descrita como deslocada, ou seja, tendo sido afastado de suas conexões africanas durante sete anos, em razão de seu exílio, perdeu parte de sua representatividade em Bonny, que já vinha sendo desgastada ao longo das décadas anteriores na disputa pelo controle da "Casa Pepple”. Por outro lado, apesar de sustentar suas demandas com um discurso humanitário e filantrópico, esbarrou na negativa do governo britânico em interferir mais diretamente para ajudá-lo a conseguir seus objetivos. Esta negativa pode ser parte coerente do discurso "oficial" britânico até á década de 1870 de não interferência, e especialmente de não anexação de territórios e contenção de despesas. Entretanto, a posição contrária do cônsul Richard Burton não deve ser desprezada. Freqüentemente a ação dos "men on the spot" forçava uma atuação intervencionista posterior da Europa. ${ }^{39}$

Não é o caso de avaliar-se positiva ou negativamente esta posição de contato. As conjunturas das sociedades costeiras africanas tornavam possível diversas formas de atuação. No caso de William Pepple, talvez um primeiro momento de negociação com a Inglaterra no qual assinou um tratado sobre o fim do tráfico escravo, ainda no final da década de 1830 , tenha sido o estopim para a sua constante perda de autoridade e riqueza em Bonny nas décadas seguintes. Por outro lado, estas conjunturas forjaram também uma série de experiências economicamente bem sucedidas, tais como o caso do próprio Ja Ja, antes de sua deportação, ou mesmo o caso dos mercadores de escravos afro-brasileiros de Ouidá, que controlavam praticamente todo o comércio exterior atlântico do reino do Daomé durante a maior parte da primeira metade do século XIX..$^{40}$

\footnotetext{
${ }^{39}$ Para a ação dos men on the spot, ver: MCYNTIRE, W. David. The Imperial Frontier in the Tropics, 1865-75, a Study of British Colonial Policy in West Africa, Malaya and the South Pacific in the Age of Gladstone and Disraeli. London: Macmillan 1967 e também "Commander Glover and the Colony of Lagos, 1861-73". The Journal of African History, vol. 4, n 1, 1963, pp. 57-79 e JACK, Sibil. Imperial Pawns: the Role of the British Consul, in SCHEUDER, Derick M. (ed.). Imperialisms, Canberra: Highland Press, 1991.

${ }^{40}$ A bibliografia sobre comerciantes de escravos em Daomé é bastante vasta. Apenas a título de exemplo, ver: SOUMMONI, Elisee. Daomé e o Mundo Atlântico. Sephis e Centro de Estudos Afro Asiáticos da Universidade Cândido Mendes, Amsterdã/Brasil, 2001.
} 
O importante é notar que a configuração política, econômica e social de Bonny nas décadas imediatamente anteriores ao período colonial não é derivada unicamente das demandas européias, mas sim de uma complexa correlação entre Europa, África e América (receptora de escravos) com diferentes formas de resistência e adaptação, tanto do lado dos africanos quanto dos europeus. Esta correlação gerou ao longo dos séculos sociedades profundamente conectadas ao mundo atlântico, em especial os estados costeiros da África Ocidental cuja própria posição geográfica colocava-os exatamente no ponto de intersecção mais permeável entre o ocidente e a África. 